\title{
Further observations and implications of Oil Palm Elaeis guineensis fruit consumption by Hooded Vultures Necrosyrtes monachus in coastal Gambia.
}

\author{
Clive R. Barlow ${ }^{1 *}$ \\ ${ }^{1}$ Birds of The Gambia, Brusubi Gardens, Western Region, The Gambia \\ * Corresponding author: birdsofthegambia@ hotmail.com
}

\section{Background}

Groups of the Hooded Vulture Necrosyrtes monachus were observed pick feeding at small piles of boiled and crushed African Oil Palm Elaeis guineensis fruit at the south Gambian village of Marakissa $\left(16.39044^{\circ} \mathrm{N}, 13.12055^{\circ} \mathrm{W}\right)$ on several occasions in the 1980s and 1990s. The vultures foraged alongside working women farmers (Barlow et al 1997). This remains the only published reference for this type of feeding habit based on direct observations. The utilisation of nonhuman harvested African Oil Palm E. guineensis fruit (also known as palm-nuts) as a food source by $N$. monachus has been described previously, derived from a road-killed bird collected on $22^{\text {nd }}$ September 2003 in coastal Gambia that was found with a stomach containing 11 fresh whole fruits of E. guineensis (Barlow 2004). The intact fruits had not been boiled, crushed or seemingly processed by farmers in the small-scale village enterprise palm oil production process. Another complete $N$. monachus specimen found in a rice field $100 \mathrm{~km}$ inland on $9^{\text {th }}$ February 2002 had five Oil Palm pits (all the fleshy mescocarp parts were missing and the seed is contained inside the pit, e.g. see Figure 3 ) in the desiccated remains (Barlow 2004). We have no reports from elsewhere of $N$. monachus feeding on Oil Palm fruit or the by-product since the 2004 report, and a photographic record of $N$. monachus foraging on Oil Palm fruit in the field remains sought after. In the context of other species, feeding on palm fruit by the Palm-nut Vulture Gypohierax angolensis is well documented (Bannerman 1930, Clark \& Davies 2018), and three fruits were found in the stomach of a desiccated carcass of an adult African Harrier-Hawk Polyboirodes typus found in the Central River Region of Gambia, February 2005 (personal observation).

\section{New observation}

On $10^{\text {th }}$ April 2020 I made a morning visit to the Ghana Town fishing village dump site in coastal Gambia $\left(16.77550^{\circ} \mathrm{N}, 13.38316^{\circ} \mathrm{W}\right)$ to survey for Afro-Palearctic migratory Western Yellow Wagtail Motacilla flava and White Wagtail M. alba. The site is also regularly monitored to make counts of Hooded Vultures. The avian scavenging guild at the dump also includes Yellow-billed Kite Milvus aegyptius, Grey-headed Gull Larus cirrocephalus, Cattle Egret Bubulcus ibis and Pied Crow Corvus albus. At 10:30 am, 18 Hooded Vultures of mixed ages, based on differing nape and head-dress patterns (Barlow et al. 1997), were seen on the ground amidst assorted refuse. Fish offal was a main component of the organic refuse with some cooked food waste and general household rubbish. I watched three Hooded Vultures busily swiping with their beaks in the surface of a small patch of bare damp ground and pick feeding for larvae and invertebrates (Figure 1). We have recently filmed and photographed Hooded Vultures digging for fly 
larvae at other sites, for example in piles of ruminant stomach content at slaughter sites; and picking for arthropods (e.g. Dermestidae beetles) at the same Ghana Town dump discussed here (personal observation). At 11:10 am, an adult Hooded Vulture arrived and stood ca. $3 \mathrm{~m}$ in front of me and began a series of retching motions which swiftly led to the disgorgement of dietary content (Figure 2). Foodstuff dropped to the ground three times in quick succession. On completion of the action the vulture walked a small distance away and did not revisit the regurgitated materials (Figure 3). None of the other vultures exhibited any interest in approaching the vomited food in order to investigate a potential feeding prospect. At other sites vultures foraging in proximity of each other have been seen to watch conspecifics retch and vomit, then move toward and ingest the regurgitated products (personal observation). After the vultures departed, I walked over to examine and photograph the evidence and collected the entire sample of regurgitated food which I identified as fresh Oil Palm fruit remains (Figure 3). On arrival home I separated out the sample with forceps and took photographs. A total of 13 fruits was counted and, by using a Pesola ${ }^{\circledR}$ spring balance, the whole wet sample was weighed at $13 \mathrm{~g}$. One fruit was fully intact and another partly intact with some exposed mesocarp. The 11 other seeds had exposed fibrous mesocarp mostly detached from the dark pit and which appeared to be partly digested and squashed of oil content (Figure 3b). No other food item was found in the sample.

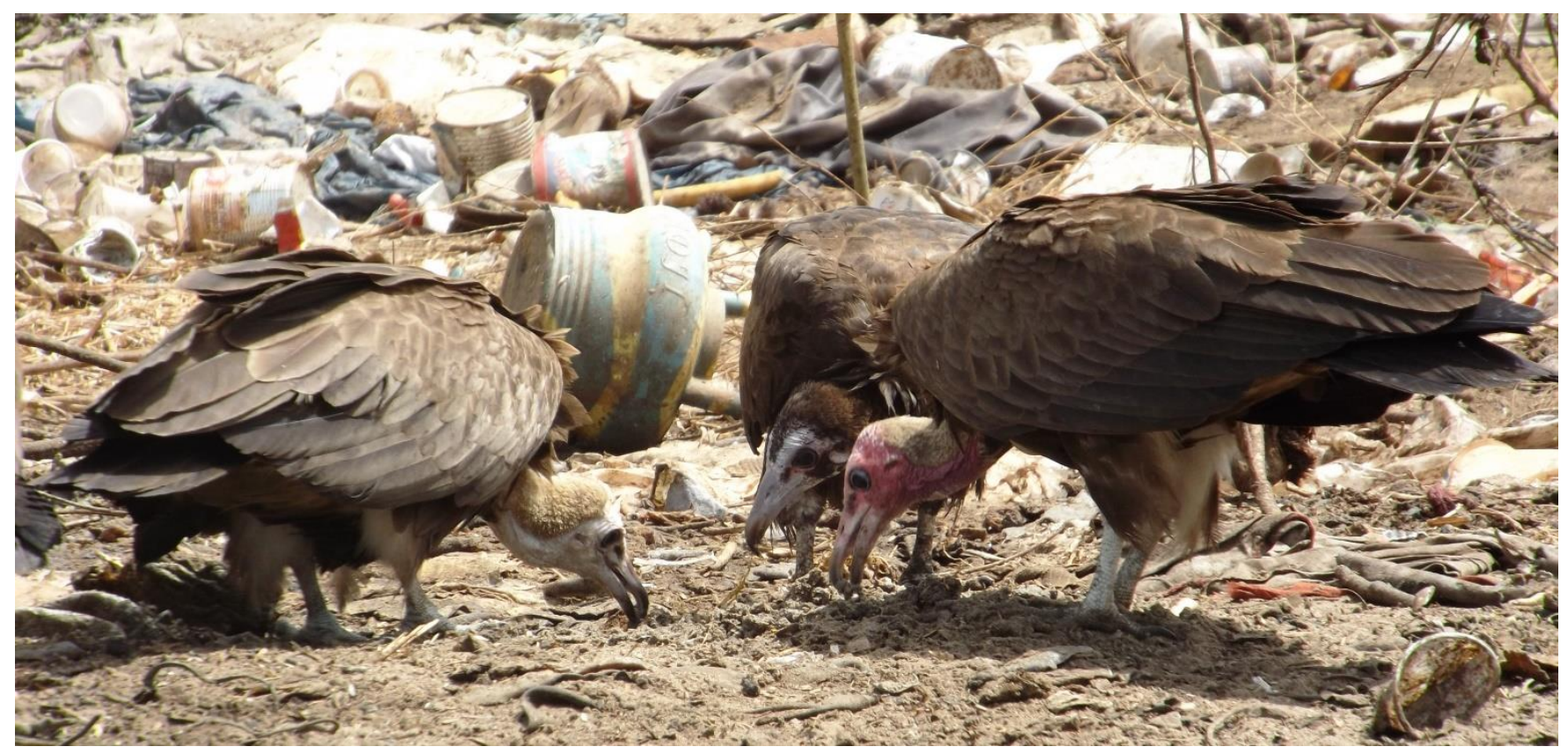

Figure 1: Three Hooded Vultures Necrosyrtes monachus pick-feeding for invertebrates after bill sweeping at a patch of ground at the Ghana Town dump site, coastal Gambia on $10^{\text {th }}$ April 2020 (Clive Barlow). 


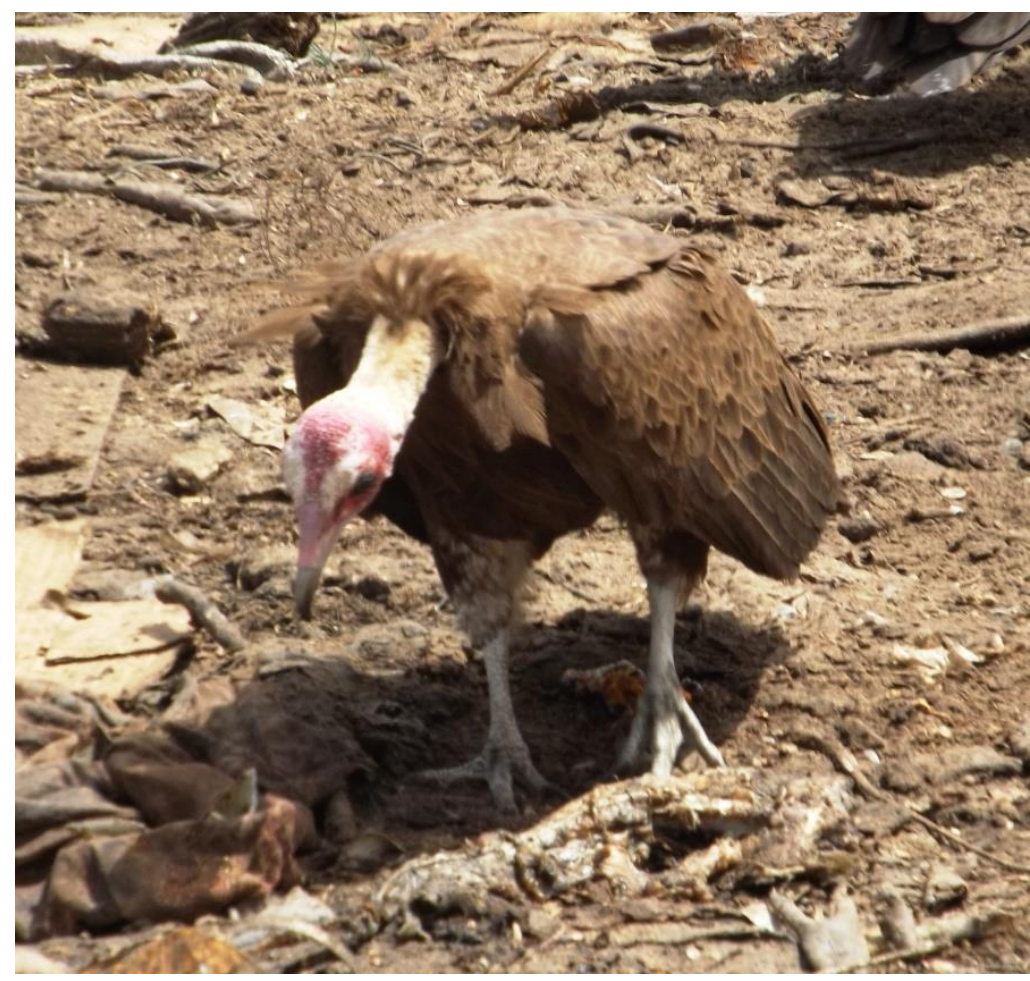

Figure 2: Adult Hooded Vulture Necrosyrtes monachus immediately prior to retching and regurgitating Oil Palm fruits on $10^{\text {th }}$ April 2020 (Clive Barlow).

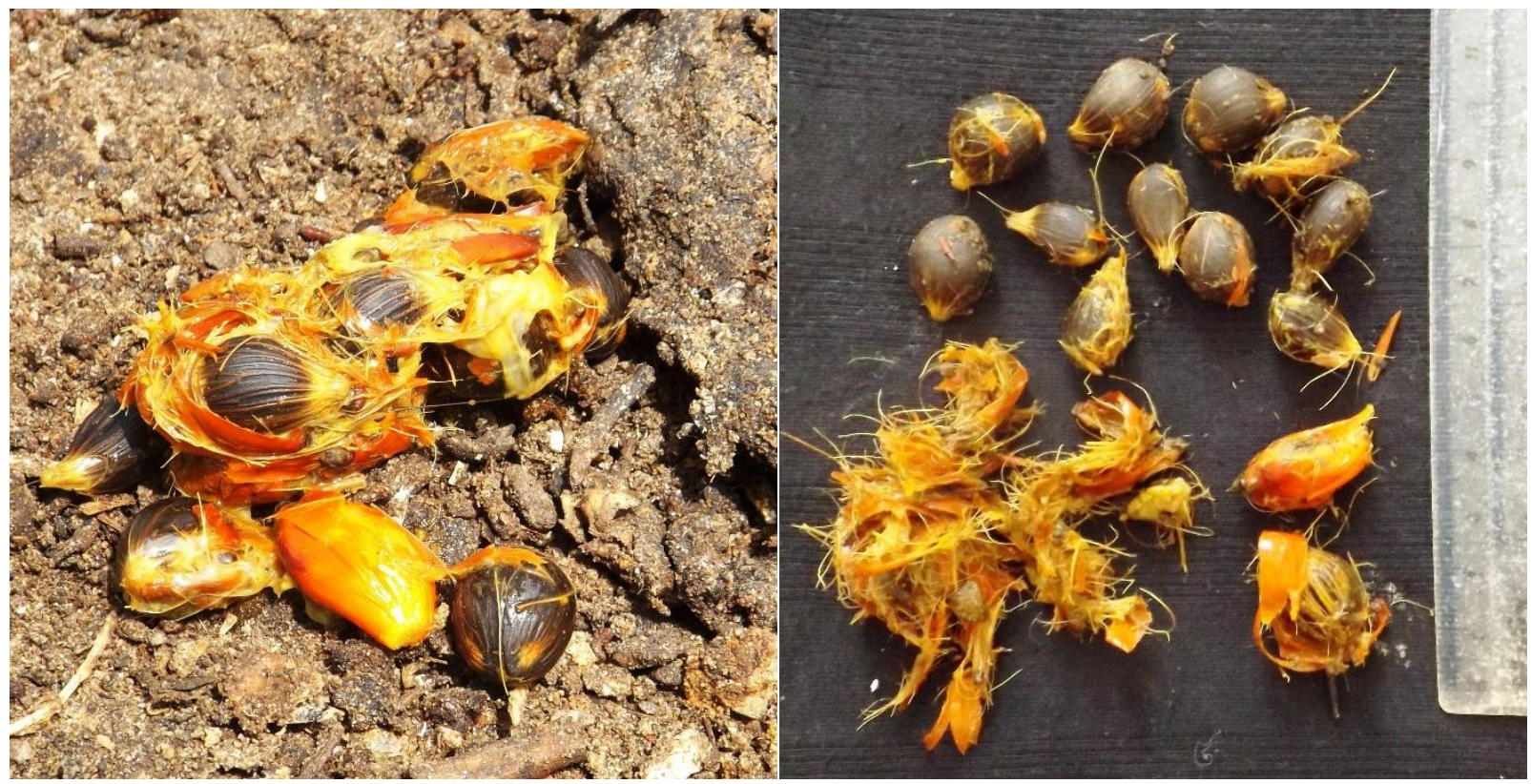

Figure 3: (a) The full sample of 13 regurgitated African Oil Palm fruits as found on the ground at the Ghana Town dump site on $10^{\text {th }}$ April 2020, showing some with orange mesocarp fibre partly detached from the hard dark pits (centre); and (b) the full sample of 13 regurgitated African Oil Palm fruits against a $150 \mathrm{~mm}$ rule, showing one intact fruit and one partly intact with some exposed mesocarp (bottom right). Eleven other seeds had a dark pit with exposed fibrous mesocarp (teased apart with forceps for the image) which appears to be partly digested, squeezed and pressed of palm oil content with a 'chewed fibrous appearance' (bottom left) (Clive Barlow). 


\section{Discussion}

There is now proof of Hooded Vultures feeding on Oil Palm fruits in The Gambia in January, April and September (assuming that the fully dried out carcass found on 9 February 2002 had died the preceding month). In recent years, the harvesting of Oil Palm fruit is generally associated with the wet season months of June to October (F. Mendy, M. Sanneh, personal communication). Therefore, any fresh-looking residual Oil Palm fruit material would be expected to be found discarded in those months. The local community members who engage in palm oil production often farm pigs and feed the entire processed fruit waste to their livestock after red oil extraction. This means that by-products are not lying around and available to the vultures for long periods after the extraction process (personal observation). It is also reported by farmers in south Gambia that local village Oil Palm processing activities are in decline. In the same communication an interesting observation was added that when Village Weavers Ploceus cucculatus are seen picking, carrying around and feeding on the Oil Palm fruits, these are positive indications to farmers of the readiness for harvesting of the infructescence bunches from the tree (R. Rugge, personal communication). Further discussions are needed with producers in village communities to help understand the activities of vultures at pre- and post-boiling events in and around the remaining palm oil processing sites. Observational surveys should be done at fruiting trees for vultures harvesting directly from the infructescence. Other possible foraging opportunities include local food markets where palm fruit is sold from open vessels and some product may be disposed of at nearby dumps. Picking up of partly eaten fruit dropped to the ground by mammals (e.g. Western Baboon Papio papio and Gambian Sun Squirrel Heliosciurus gambianus (personal observation)) foraging in palm tree crowns is also a possible source. Likewise, cooking areas in domestic compounds when portions of stored fruit could be pounded for use in food preparations at any time of the year should be watched. This would help to identify where Hooded Vultures are finding and consuming the whole fruits of E. guineensis across all seasons and the frequency with which this occurs.

Despite being widely distributed in sub-Saharan Africa, the Hooded Vulture has suffered severe population declines across the entire range and is currently listed as Critically Endangered by the IUCN (BirdLife International 2017). Highly commensal West African birds differ considerably in feeding behaviour and in general ecology from their East and southern African conspecifics, although more research is needed in this area (Barlow et al. 2020). There are also huge variations in home ranges between regional populations as proven by satellite tracking studies (Reading et al. 2019, Thompson et al. 2020). Most other countries in West Africa are reporting serious declines, for example in Senegal (Mullié et al. 2017) and Nigeria (Nosazeogie et al. 2018). Based on a set of road surveys carried out in 2013 and 2015 the population estimate of N. monachus in an area of ca. $600 \mathrm{~km}^{2}$, suggests population densities of 7,000-10,500 in coastal Gambia, or 4-5\% of the currently estimated global population, in an area that represents less than $0.0001 \%$ of the species' range (Jallow et al. 2016). The Gambia therefore supports globally important numbers of Hooded Vulture (Jallow et al. 2016), and recent surveys of a route first studied in 2005 (Barlow \& Fulford 2013) are pointing towards a significant increase in vulture numbers along the same stretch of road (Barlow \& Cryer in prep.). We believe that a factor contributing to this apparent increase is associated with the diverse range of organic food items utilised by this versatile and 
highly human commensal scavenger in The Gambia.

Present study of Hooded Vultures in this part of The Gambia reveals the exploitation of an extremely varied food resource scavenged in a diverse range of situations. Congregations of vultures, in some cases numbering low hundreds occur at abattoirs, bustling fish landing sites and their associated organic waste dumps, butcheries on the outskirts of villages and at domestic animal roadkill on busy highways. Livestock markets, vulture feeding displays in hotels created for tourist entertainment and street grill 'afra' meat kiosks are also visited. High numbers of vultures also congregate at stranding events of sea turtle and cetacean species, and the whole coastline provides a supply of miscellaneous seafood. Other examples that illustrate the diverse foraging behaviour of Hooded Vultures in the region include groups of birds rushing to consume liquid blood when it is provisioned by butchers at slaughter sites; wading into the shallows and feeding on partly submerged large dead fish rolling in the tideline; digging and raking for maggots and arthropods at waste sites; and up to 30 birds assembling and hunting for live Fiddler Crabs Afruca tangeri on the edge of Avicennia mangrove close to the seaboard at low tide (personal observation, first witnessed July 2014). Much lower numbers frequent the handful of large active municipal rubbish dumps in coastal Western Region (Barlow \& Cryer in prep.).

A focused study to identify and assess the key factors currently supporting this apparently stable or increasing population of Hooded Vultures in coastal Gambia is recommended. The daily contribution to ecosystem services by ca. $9000 \pm$ 2000 highly mobile obligate scavengers provides a crucial role in the removal of large volumes of organic waste and carrion, the level of which should be assessed and quantified. A review of attitudes towards vultures, and particularly Hooded Vultures, amidst Gambian cultures and beliefs is needed. Results from these and other investigations would inform the development of education and awareness packages pertinent to The Gambia and neighbouring countries, as well as other conservation actions.

\section{Acknowledgements}

Duncan Thomas made constructive comments on an earlier draft and advised on correct botanical terminologies associated with fruit of the African Oil Palm. I thank Francis Mendy, Ria Rugge and Mariama Sanneh (DPWM) for contributing local knowledge. Jason Waine assisted throughout and Nigel Harcourt-Brown also helped with questions dealing with the digestive tract. An anonymous referee is thanked for prompting constructive ideas and making useful comments on an earlier draft.

\section{References}

Bannerman, D.A. 1930. The Birds of Tropical West Africa, Vol. 1. Crown Agents. London.

Barlow, C.R., Wacher, T. \& Disley, T. (1997) Field Guide to Birds of The Gambia and Senegal. Pica Press. Mountfield.

Barlow, C.R. 2004. The utilization of oil-palm kernel by Necrosyrtes monachus in The Gambia. Vulture News 51: 60-62. 
Barlow, C.R. \& Fulford, T. 2013. Road counts of Hooded Vultures Necrosyrtes monachus over seven months in and around Banjul, coastal Gambia, in 2005. Malimbus 35: 50-56.

Barlow, C.R., Reading, R. P., Shema, S. \& Maude, G. 2020. Homogeneity in cranial biometrics and bill morphology is verified by measurements from The Gambia, Botswana and Kenya in the case of the putative sub-species of the highly commensal Hooded Vulture Necrosyrtes monachus monachus and non commensal Necrosyrtes monachus pileatus. Vulture News 78: 1-10.

BirdLife International. 2017. Necrosyrtes monachus (amended version of 2017 assessment). The IUCN Red List of Threatened Species 2017: e.T22695185A118599398. https://dx.doi.org/10.2305/IUCN.UK.2017-3.RLTS.T22695185A118599398.en. Downloaded on 08 May 2021.

Clark, W.S. \& Davies R. 2018. African Raptors. Bloomsbury Helm. London.

Jallow, M., Barlow, C. R., Sanyang, L., Dibba, L., Kendall, C., Bechard, M., \& Bildstein, K. L. 2016. High population density of the critically endangered Hooded Vulture Necrosyrtes monachus in Western Region, The Gambia, confirmed by road surveys in 2013 and 2015. Malimbus 38: 23-28

Mullié W.C., Couzi F., Diop M.S., Piot B., Peters T., Reynaud P.A., \& Thiollay J. 2017. The decline of an urban Hooded Vulture Necrosyrtes monachus population in Dakar, Senegal, over 50 years. Ostrich 88: $131-138$.

Nosazeogie, E. \& Tende, T. \& Monadjem, A. 2018. Hooded Vultures Necrosyrtes monachus nearly extirpated from Edo State, Nigeria: a report on the avian scavenger community. Ostrich 89: 265-273

Reading, R. P., Bradley, J., Hancock, P., Garbett, R., Selebatso, M., \& Maude, G. 2019. Home range size and movement patterns of hooded vultures Necrosyrtes monachus in southern Africa. Ostrich 90: 7377.7

Thompson, L. J., Barber, D., Bechard, M., Botha, A. J., Wolter, K., Neser, W., Buechley, E. R., Reading, R., Garbett, R., Hancock, P., Maude, G., Virani, M. Z., Thomsett, S., Lee, H., Ogada, D., Barlow, C. R. \& Bildstein, K. L. 2020. Variation in monthly sizes of home-ranges of Hooded Vultures Necrosyrtes monachus in western, eastern, and southern Africa. Ibis, 162: 1324-1338. 